\title{
Long QT syndrome
}

\author{
Heather Jackson BSc, Lee-Anna Huisman MSc, Shubhayan Sanatani MD, Laura T. Arbour MSc MD
}

Competing interests: None declared.

This article has been peer reviewed.

Correspondence to: Dr. Laura T. Arbour, larbour@uvic.ca

CMAJ 2011. DOI:10.1503 /cmaj.100138
I n a First Nation community located northeast of Haida Gwaii in British Columbia, a 38-year-old woman required resuscitation from an apparent cardiac arrest that had occurred while she was coaching at a competitive sports event. She had a history of syncope and palpitations. Her family history included a brother who had died unexpectedly as an infant and an aunt who had died suddenly at the age of 15 years.

In the same community, a 37-year-old woman had a prolonged QT interval corrected for heart rate (QTc) on electrocardiograms (ECGs), a history of frequent palpitations and brief episodes of altered consciousness and weakness. Her family history included sudden, unexplained death in a newborn sibling and in a sister aged 32 years.

The women were diagnosed with long QT syndrome. Clinical genetic sequencing showed they both had a G-to-A substitution in exon 4 of the $K C N Q 1$ gene, resulting in a novel valine-tomethionine amino acid change at position 205 of the protein $(\mathrm{V} 205 \mathrm{M})$. Mechanistic studies subsequently established mutation pathogenicity. ${ }^{1}$ These two patients were not known to be related within four generations. The long QT syndrome in both women was managed with implantable cardioverter defibrillators.

In a second First Nation community also located northeast of Haida Gwaii, a four-year-old girl complained that her "heart was jumping." Several ECGs were performed, and community physicians made a clinical diagnosis of long QT syndrome. The child's paternal aunt had died suddenly after childbirth at age 26 , and her father had lost two other siblings as infants to sudden,

\section{- Ker POINTS}

- Congenital long QT syndrome, an autosomal dominant condition, predisposes affected people to cardiac arrhythmias and sudden cardiac death.

- Sudden cardiac death can be prevented by appropriate medical management such as $\beta$-blockers and avoidance of QT-prolonging drugs.

- Because two different mutations have been confirmed in two First Nation communities in northern British Columbia, clinicians should consider the possibility of long QT syndrome in members of these communities. unexplained death. Because the child's grandmothers were both ancestrally from community one, it was presumed this family would also carry the KCNQ1 V205M mutation. However, targeted testing was negative for this mutation, and comprehensive molecular testing was done for the five most common long QT syndrome genes: $K C N Q 1, K C N H 2, S C N 5 A, K C N E 1$ and KCNE2. Sequencing confirmed that the child and her father shared a different mutation in $K C N Q 1$, $\mathrm{R} 591 \mathrm{H}$, which has been previously characterized as a pathogenic mutation. ${ }^{2}$ Other family members have been confirmed as mutation carriers, and a history of sudden, unexplained death can be traced back at least five generations. To date, long QT syndrome in this family has been managed effectively with $\beta$-blockers.

\section{Discussion}

Long QT syndrome is a rare, inherited cardiac condition associated with life-threatening ventricular arrhythmias. An estimated $80 \%$ of hereditary long QT syndrome is caused by more than 500 mutations in 12 genes (Appendix 1, available at www.cmaj.ca/lookup/suppl /doi:10.1503/cmaj.100138/-/DC1) that encode ion channels or functionally related proteins involved in cardiac conduction., ${ }^{3,4}$ Minor gene effects may play a role in the presentation of long QT syndrome, ${ }^{3}$ and a combination of mutations and functional polymorphisms may result in a more severe phenotype with a greater risk of sudden death. ${ }^{5}$ Intense emotions or exogenous triggers such as QT-prolonging drugs can also compound the effect of a mutation, which reinforces the multifactorial and complex nature of the condition. Although long QT syndrome in the communities described in this paper is caused by two different mutations in the $K C N Q 1$ gene, the clinical presentation and family history are similar.

\section{How common is it?}

The incidence of inherited long QT syndrome in the general population is predicted to be $1: 2500{ }^{4}$ 
However, clusters of affected individuals have been seen in ethnically homogenous or isolated populations, presumably because of the familial nature of the condition and founder effect. ${ }^{3}$

For example, in the first community described in this paper, members of the community alerted university researchers to the need to investigate the high rate of long QT syndrome in the community. A research protocol was developed with the community, and relatives of the two index patients were invited to participate in a community-based research project. ${ }^{1}$ To date, more than 300 people who originate from this community have participated in the project. Fifty-eight people have been confirmed to be mutation carriers.

For clinicians providing care in northern British Columbia, it is important to be aware that the estimated frequency of this mutation of at least 1:125 in the two communities described in this paper is 20 times greater than the predicted rate in the general population and among the highest worldwide (map of the general region of the $\mathrm{BC}$ communities available at Appendix 2, www.cmaj.ca/lookup /suppl/doi:10.1503/cmaj.100138/-/DC1).

\section{How is the diagnosis made?}

The clinical diagnosis of long QT syndrome is made on the basis of a prolonged QTc interval, for which the cut-off remains controversial (Table $1^{3,6}$ ), or the presence of a known pathogenic long QT syndrome mutation. However, $30 \%-40 \%$ of those affected will be either underor overdiagnosed because of equivocal QTc measurements. In the first community, carriers have a significantly higher mean QTc (Figure 1) than noncarriers (465 [standard deviation 28] ms v. 434 [standard deviation 26] ms, $p<0.0001$ ); however, $30 \%$ of carriers had at least one ECG with a QTc below 440 ms. ${ }^{1}$ Sex-specific differ- ences in clinical findings can further complicate diagnosis. In the first community, for example, there is no apparent difference in the QTc between male V205M mutation carriers and noncarriers, ${ }^{1}$ although this finding is limited by the fact that few men enrolled in the study.

\section{What is the prognosis?}

The lifetime risk of death in long QT syndrome is reported to be between $15 \%$ and $70 \%$, but varies with the gene involved, age, sex and length of the QT interval. ${ }^{3}$ The risk for death is highest in the two years following the first cardiac event. ${ }^{3}$ The overall mortality risk can be substantially reduced with appropriate treatment, which is dictated by the ion channel involved. Therefore, health care providers must be alert to the possibility of the syndrome, be vigilant when reviewing ECG findings and ensure genetic testing is started for all patients with clinical features of the syndrome or those who are firstdegree relatives of a mutation carrier.

The standard medical treatment for the most common type (type 1) of long QT syndrome, caused by mutations in $K C N Q 1$, is oral $\beta$-blockers. ${ }^{3}$ In a minority of cases, such as when cardiac arrest has occurred, or when $\beta$-blockers are contraindicated or ineffective, implantable cardioverter defibrillators are considered. ${ }^{3}$ In a recent study, noncompliance with medications or exposure to QT-prolonging drugs was associated with important cardiac events; ${ }^{7}$ this suggests that when patients who are carriers of a $K C N Q 1$ mutation take $\beta$-blockers regularly and avoid QT-prolonging drugs, the risk of death may be eliminated. $\beta$-blockers are not without adverse effects, and patients might not comply with treatment advice.

Further longitudinal research to determine the specific risk for serious cardiac events and opti-

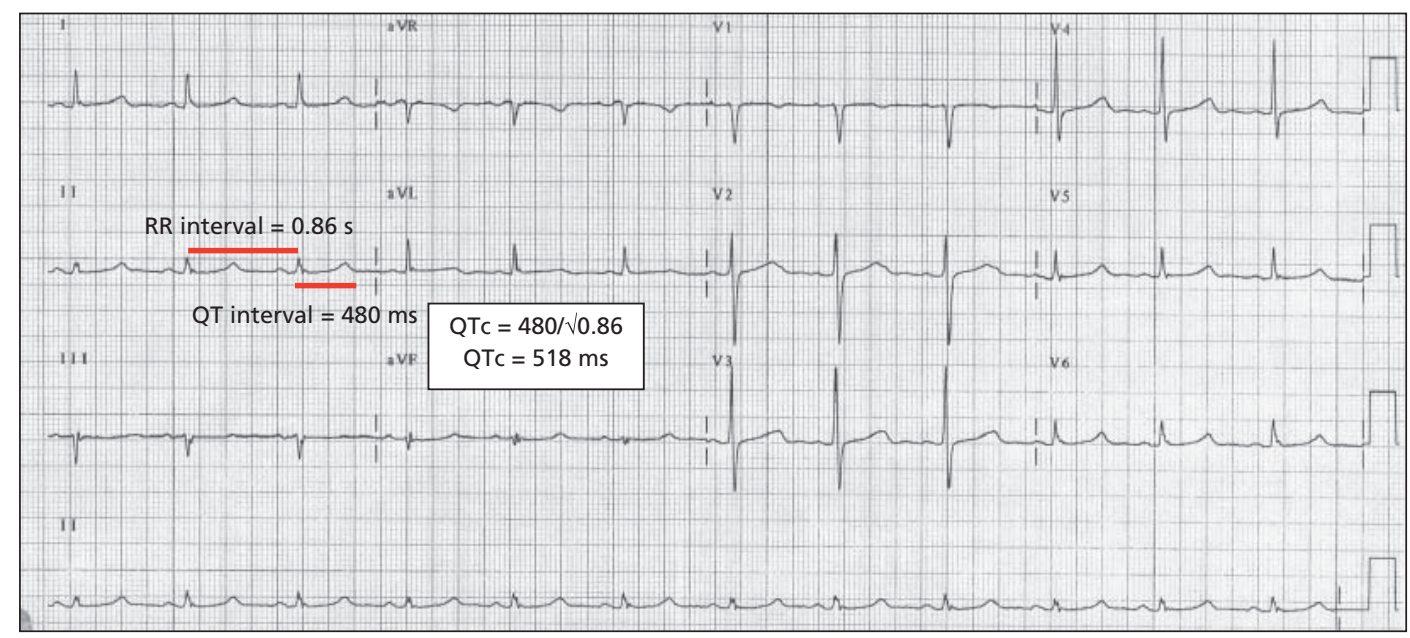

Figure 1: Example of a 12-lead electrocardiogram in a participant from community one with a heterozygous KCNQ1 V205M mutation. QTc = QT interval corrected for heart rate. 
mal management strategies is essential in establishing and providing the most effective clinical management. ${ }^{3}$ For now, based on the evidence for the effectiveness of $\beta$-blockers in carriers of a $K C N Q 1$ mutation, pharmacologic treatment should be started even if patients are otherwise asymptomatic.?

\section{QT-prolonging drugs}

The avoidance of QT-prolonging drugs is challenging. More than 300 drugs, as seemingly benign as antibiotics or as common as antidepressants, are known to potentially trigger events (Table 2). ${ }^{8}$ Additionally, for about $15 \%$ of asymptomatic people with confirmed long QT syndrome, the first clinical indication of the condition is sudden cardiac death. ${ }^{3}$ Therefore, it is essential that carriers of the mutation avoid QT-prolonging drugs and other known triggers, even when there is no obvious prolongation of the QT interval.

\section{Psychological effects}

Another important aspect of clinical care to consider for these patients is the psychologic impact of long QT syndrome. The emotional impact of learning that one has inherited a predisposition to sudden cardiac death or that one's children are at risk or affected can be profound. ${ }^{9}$ The perception that primary care physicians have little knowledge about this generally rare condition can raise anxiety levels even further. ${ }^{9}$ This may be a particular concern for those in remote areas that are served by rotating or locum clinicians, who may not be aware of the local impact of the condition. Therefore, in addition to physical management, it is important to ensure that psychologic support, including counselling, is available.

\section{Conclusion}

The diagnosis of long QT syndrome presents challenges to the patients, families and their health care providers. A high rate of long QT syndrome (type one) is present in First Nation people who originate from northern British Columbia, with two different, pathogenic muta-

\begin{tabular}{|lcc|}
\hline \multirow{2}{*}{$\begin{array}{l}\text { Table 1: Interpretation of QTc intervals } \\
\text { in adults }\end{array}$} \\
\hline \multirow{2}{*}{ Interpretation } & \multicolumn{2}{c|}{ QTc, ms } \\
\cline { 2 - 3 } & Men & Women \\
\hline Abnormal & $\mathbf{4 5 0}$ & $\geq 460$ \\
\hline Normal & $390-450$ & $390-460$ \\
\hline Note: QTc = QT interval corrected for heart rate. \\
\hline
\end{tabular}

tions responsible. Although a prolonged QTc on ECG may be predictive of a mutation, a negative ECG does not rule it out. The identification of these mutations has provided physicians with a valuable diagnostic test for the relatives of a mutation carrier. However, as migration throughout Canada is inevitable, those affected will present well beyond the confines of the community borders. Therefore, health care providers must exercise caution when prescribing QT-prolonging drugs to First Nation people from northern British Columbia who show evidence of a prolonged QT interval or are related to those with long QT syndrome. The importance of exploring a family history of this syndrome should not be overlooked and could be life-saving when prescribing medications, because appropriate management will improve the chance of survival of those at risk.

Future studies in these communities are planned to address knowledge gaps, including sex-specific differences in the clinical phenotype, the role of secondary mutations, and factors that may hinder or support coping in affected families. Ongoing monitoring of patients molecularly identified with the condition will provide more information on the natural history of the syndrome in these communities and, in turn, will improve management strategies and patient care.

Table 2: Examples of generic medications found to prolong QT intervals*

\begin{tabular}{|lc|}
\hline $\begin{array}{l}\text { Generic drug } \\
\text { name }\end{array}$ & \multicolumn{1}{c|}{ Function } \\
\hline Ciprofloxacin & Antibiotic \\
\hline Clarithromycin & Antibiotic \\
\hline Erythromycin & Antibiotic, Gl stimulant \\
\hline Tamoxifen & Anticancer \\
\hline Citalopram & Antidepressant \\
\hline Fluoxetine & Antidepressant \\
\hline Paroxetine & Antidepressant \\
\hline Sertraline & Antidepressant \\
\hline Diphenhydramine & Antihistamine \\
\hline $\begin{array}{l}\text { Terfenadine } \\
\text { Quetiapine }\end{array}$ & Antihistamine \\
\hline Albuterol & Antipsychotic \\
\hline Ephedrine & Bronchodilator \\
\hline $\begin{array}{l}\text { Methylphenidate } \\
\text { Pseudoephedrine }\end{array}$ & Bronchodilator, decongestant \\
\hline Methadone & Decongestant \\
\hline $\begin{array}{l}\text { Note: CNS }=\text { central nervous system, Gl = gastrointestinal. } \\
{ }^{*} \text { A complete and up-to-date list can be found at } \\
\text { www.azcert.org/medical-pros/drug-lists/CLQTS.cfm. }\end{array}$ \\
\hline
\end{tabular}




\section{References}

1. Arbour L, Rezazadeh S, Eldstrom J, et al. A KCNQ1 V205M missense mutation causes a high rate of long QT syndrome in a First Nations community of northern British Columbia: a community-based approach to understanding the impact. Genet Med 2008; 10:545-50.

2. Grunnet M, Behr ER, Calloe K, et al. Functional assessment of compound mutations in the KCNQ1 and KCNH2 genes associated with long QT syndrome. Heart Rhythm 2005;2:1238-49.

3. Goldenberg I, Zareba W, Moss AJ. Long QT syndrome. Curr Probl Cardiol 2008;33:629-94.

4. Schwartz PJ, Stramba-Badiale M, Crotti L, et al. Prevalence of the congenital long-QT syndrome. Circulation 2009;120:1761-7.

5. Gargus JJ. Unravelling monogenic channelopathies and their implications for complex polygenic disease. Am J Hum Genet 2003;72:785-803.

6. Rautaharju PM, Surawicz B, Gettes LS. AHA/ACCF/HRS recommendations for the standardization and interpretation of the electrocardiogram. Part IV: the ST segment, T and U waves, and the QT interval. A scientific statement from the American Heart Association Electrocardiography and Arrhythmias Committee, Council on Clinical Cardiology; the American College of Cardiology Foundation; and the Heart Rhythm Society. Circulation 2009;119:e241-50.

7. Vincent GM, Schwartz PJ, Denjoy I, et al. High efficacy of $\beta$ blockers in long-QT syndrome type 1 contribution of noncompliance and QT-prolonging drugs to the occurrence of $\beta$-blocker treatment "failures." Circulation 2009;119:215-21.

8. Drugs to be avoided by patients with congenital long QT syndrome (CLQTS) [website of the Arizona Center for Education and Research on Therapeutics]. Available: www.azcert.org /medical-pros/drug-lists/CLQTS.cfm (accessed 2010 Jan. 17).
9. Farnsworth MM, Fosyth D, Haglund C, et al. When I go in to wake them ... I wonder: parental perceptions about congenital long QT syndrome. J Am Acad Nurse Pract 2006;18:284-90.

Affiliations: From the Department of Medical Genetics (Arbour, Huisman), University of British Columbia, Vancouver, BC; the Island Medical Program (Arbour, Jackson), Victoria, BC; and the Department of Pediatrics (Sanatani), BC Children's Hospital, Vancouver, BC

Contributors: All authors wrote and revised the manuscript, and approved the final version submitted for publication.

Acknowledgements: This teaching case report has been reviewed and approved by the UBC Research Ethics Board and the Gitxsan Health Society Board. Members of both communities have reviewed and approved earlier versions of this manuscript. The authors thank their community-based partners, especially Sheri Martin, Gwen Simms and Julia Sundell. The authors also thank Rosemarie Rupps, Sarah McIntosh, Samantha Lauson, Brett Casey, Stanley Tung and Charles Kerr from Provincial Health Services Authority; Laurence Sterns, Paul Novak, Richard Leather, Brian Sinclair and Anthony Tang from Vancouver Island Health Authority; and George Deagle and Pam Kryskow from the Northern Health Authority for their clinical contributions. This work was funded by the Canadian Institutes of Health Research grant no. 81197 to Laura Arbour and Shubhayan Sanatani. Laura Arbour also holds a career salary award through the Michael Smith Foundation for Health Research. 